\title{
Contracting for child health services in the community
}

\author{
Leon Polnay, Hilary Bingham, Rashmin Tamhne
}

\section{Introduction and background}

The reorganisation of the health services in the UK has divided responsibility for health services into the 'purchasers' who have responsibility for deciding what services are needed by the people served by the district health authority and how the budget can be spent to best advantage and the 'providers' who are contracted to provide this service. The purchasers are the district health authorities, the family health service authorities (FHSA), and fund holding general practitioners. The providers may be individual general practitioners, community and hospital units and trusts, or a combined child health service embracing both hospital and community based care. The British Paediatric Association (BPA) has produced a report, Community Child Health Services: an information base for purchasers, whose aim is to provide professional guidance to the purchasers as to the range and content of services that should be provided. ${ }^{1}$

A vision is needed of the overall shape of the service and the unique characteristics of children's services. The Court report (1976) had such a view stressing the need for a service that is child and family centred; that looks at the needs of the child as a whole; and that is provided for every child by professionals trained and experienced in the special needs of children. ${ }^{2}$ The role of parents as the prime carers and providers must be acknowledged as must the importance of prevention. The title of the Court report, Fit for the Future, is fully in tune with modern concepts of long term health gain.

Services for children are complex and do not fit tidily into the model of providing single and discrete services such as in the case of hip replacements. The services are multidisciplinary and interagency making it difficult to extract individual service elements. There is indeed a complex matrix of services and programmes that flows across ages, services, disciplines, and localities. It is quite difficult to define the boundaries between different service elements as in this jigsaw the pieces overlap by design. 'Community services' can only be provided locally and competition in the market place becomes in practice cooperation.

\section{Need for a meeting}

A task group was organised by Trent Regional Health Authority in September $1991^{3}$ to explore the inter-relationships between the FHSA and the community units in the region including the provision of child health surveillance. In the course of this task group and subsequent discussion several questions emerged. The purchasers have the responsibility for making contracts, but the expert body of opinion as to the content of those services is found in the providers. Dialogue therefore needs to take place between these two groups to exchange ideas and concepts. Programmes of care may need to be provided from several sources if there is to be overall benefit for the population. For example screening for hearing impairment may begin with neonatal screening in hospital units; it will continue in the community through child health clinics based in primary health care teams and in community units; contracts have to be placed with centres for assessment and management of children with hearing impairments; the local authority will have to provide services to these children as 'children in need' as defined by the 1989 Children Act; special educational provision may be needed; and someone must have an overview of the whole process and its effectiveness. This is not an isolated complicated issue in child health: most paediatric problems involve this or a greater level of interdisciplinary, interagency, and 'interunit' or 'intertrust' coordination or chaos. The existence of more than one purchasing agency further enhances the need for a joint strategy for purchasing if the market place is not to become a scene of disorder.

The meeting reported here was for these reasons set up to explain and discuss these important elements in the contracts for community child health services and their implementation.

\section{Structure of the meeting}

Delegates to the meeting were well briefed with background reading to the day's presentations including the BPA's guidelines for purchasers. They received overviews of community child health services from the points of view of health (the combined child health service), education (special educational needs), and social services (children in need). Summaries were presented of the principal areas for contracts contained within the BPA document: preschool children, those of school age, disadvantaged children, children with disabilities, and services for child protec- 
tion. In addition, the provision of outpatient type paediatrics in a community setting (ambulatory paediatrics) was presented. The brief descriptions of each service were reinforced by case histories of real children to remind everyone of the clinical realities that underlie contracts.

\section{Overview of needs for child health services in the NHS}

(1) SERVICES FOR PRESCHOOL CHILDREN

The content of the child health surveillance programme in the UK is agreed and published in Health for All Children. ${ }^{+}$The new contract for general practitioners ${ }^{5}$ has led to a large and continuing shift in the provision of child health surveillance from the community units and trusts to primary health care teams. Within community paediatrics, the development of a consultant led specialist service has led to a shift in provision from primary to secondary care with a concentration upon children with special needs. 'Special needs' as a term requires some definition as not all people mean the same. It was originally used to describe the one in five children whom the Warnock committee report described as in need of additional educational provision at some time in their schooling. ${ }^{6}$ It now seems to be widened to include all children with longstanding problems be they educational, medical or social, merging into the "children in need' concept in the 1989 Children Act. ${ }^{7}$ In reality all children have the same basic needs: what are special are the extra resources that have to be purchased to meet those needs. However, the community paediatrician has the opportunity to retain and develop the role of overviewing the health needs of children in the community and to support the primary health care teams with a locally based specialist paediatric service.

How then are purchasers to reach decisions in this rapidly evolving situation? Community paediatric teams provide a suitable vehicle for these service elements, ${ }^{8}$ which include training and support to primary health care teams, liaison with local education and social service departments, and the provision of a locally based referral service. The community paediatric team was originally described in the context of a more primary care oriented child health service. In our terms it now consists of community paediatricians, specialist health visitors, school nurses, and therapy staff. Advantages for the purchaser are lower cost in comparison with hospital based services and enhanced opportunities for liaison between primary and secondary care and with the local authority. Targets for health gain from this joint enterprise with family doctors will include prevention of ill health through immunisation, early diagnosis and intervention, improved childhood nutrition, and reduction in accidents. These targets are shared with the white paper, Health of the Nation. ${ }^{9}$ The community paediatricians have specialist skills to offer in prevention as well as in the role of secondary paediatric care, including general paediatrics, children with complex handicaps, and children at special risk such as those in social service day nurseries.

\section{(2) THE NEEDS OF THE LOCAL AUTHORITY SOCIAL} SERVICES

The 1989 Children Act among its provisions requires services to be provided for children in need and cooperation between health and social services. ${ }^{7}$ A wide range of service elements may be included within this interface and which require a specialist paediatric input: assessment of children in day nurseries and family centres; children 'looked after' by the local authority in community homes; advice on fostering and adoption; travelling families and homeless families; the assessment and management of children who have been abused; programmes for health promotion and accident prevention; early intervention programmes. The local authority may not be purchasers in the strict sense of the word, but there are duties to provide services. Long term health gain may be achieved through early intervention programmes targeted on this vulnerable group of children and their families.

Child protection work, like all our examples, is multifaceted requiring a great deal of cooperation between agencies over a broad range of problems including neglect and physical, sexual, and emotional abuse. The price of failure is high and the risk of failure is very much increased where services, however good, do not work together. Contracts should reflect this need.

Disadvantaged children have not only much to gain in health terms, but their much higher morbidity leads to heavy health service usage for acute problems and an increase in long term disability arising from them. The children will also gain by initiatives to support parents and enhance developmental progress.

Joint planning with the local authority is needed, aiming at long term health gain. A short term view is not useful. The interaction between health and social service policy must be appreciated. Social services need to appreciate the importance of general medical as well as specialist services and of the transition from child health to adult provision.

\section{(3) PAEDIATRIC SUPPORT FOR SCHOOLS}

Education authorities and schools require a health service for their children. This service is currently under review. A national working party on the health needs of children of school age has been convened by the BPA and will report in two years' time. The term 'health services for children of school age' is preferred to 'school health services' in that the former term implies an integration of the services to meet their health needs: this includes services provided in school, in school clinics, in child development centres, in hospital wards and outpatient departments, in general practitioner surgeries, in the home, and in residential care. Part of the health care of these children is linked to legislation, such as the 1981 Education Act and the 1989 Children Act. School health services currently provide a surveillance programme for all children and a range of specialist services to assess and support children with special needs. They have important roles in understanding the interaction between health and children's ability to learn. They are involved 
in counselling and the promotion of healthy lifestyles. They act to coordinate health at school with health services outside of school and liaise closely with teachers and social workers. This service is multidisciplinary involving medical, nursing, and therapy staff.

The programmes of health care provided in special and ordinary schools must be in tune with the policies of the education authority. Changes, for example, towards integration or greater local provision for children with particular disabilities will have very large implications for the volume and distribution of health service resources. Planning needs to be long term across the 11 years or more of full time education in order to gain the maximum benefit. Caseloads for nurses and doctors should be realistic if something better than a token service is to be provided, for example one school nurse per $1600-1800$ pupils in ordinary schools. School nurses should be able to make direct referrals, for example to eye clinics. The provision of health services at school is an efficient programme, with a high volume of consultations and a low referral rate as shown by table 1 .

Table 1 Outcomes of children seen in Nottingham school health services fanuary-April 1992

\begin{tabular}{lrc}
\hline & Seen & Referred \\
\hline Eye clinics & 486 & 46 \\
Enuresis & 166 & 2 \\
Audiometry & 2137 & 358 \\
Special medical examinations & 513 & 60 \\
Minor ailments, injuries treated by school & 6370 & 330 \\
$\quad$ based nurses & 8199 & 109 \\
\hline Immunisations(BCG) & & \\
\hline
\end{tabular}

\section{(4) GENERAL PAEDIATRICS IN THE COMMUNITY}

The consultant led community paediatric service should not only be involved in preventative child health but also in the curative management of child health problems in the community. Many of the general paediatric problems that are at present seen in hospital outpatient departments could quite easily be seen at local health centres. This ambulatory paediatric service provided by the community paediatric teams should be integrated with hospital based services in order to avoid duplication and to provide the best and most appropriate care for every child.

\section{Table 2 Important themes emerging from the seminar}

Information

Need for research

Emphasis of health promotion

Importance of long term health gain

Parent held records provide an excellent vehicle for communication and integration

Purchasing is for families and the views of the local people are important

Different provider structures

Programmes cross provider boundaries

Health gain is linked to targets

Health gain may be in short, medium, or long term

Need for investment in training in communication and team work

Need for information to monitor contracts

Need to highlight quality issues

Need for a common understanding of the terms primary, secondary, and tertiary care

Joint purchasing (district health authority/FHSA) backed by joint needs assessment

Impact of general practitioner fundholders looking to influence the way the service is run
Such an integrated approach based in health centres, cottage hospitals, and some general practitioner practices is running successfully in Leicestershire. It allows delivery of a high quality of paediatric care within the local community. It is particularly suitable for areas of deprivation. It also facilitates contact between consultant community paediatricians and general practitioners, enhancing the quality of care received by children.

\section{(5) SERVICES FOR CHILDREN WITH DISABILITIES} Services for children with disabilities provide yet another complex model with a range from early diagnosis, through to multidisciplinary assessment and management. Important issues are continuity of care, integration of the various elements of care (the seamless service), and transition into adult life. There is scope for creative interagency approaches.

\section{Topics from afternoon group discussions}

The following topics were discussed during the afternoon session in five groups.

- How should contracts be constructed to meet the needs of client groups?

- How do you contract for health promotion within the purchasing of child health services?

How can purchasers ensure that an integrated child health service is achieved?

How would you identify opportunities for health gain?

Whose priorities?

The group discussions led to some common themes emerging (table 2). The complexity of service networks requires good information systems if purchasers are to make sense of what they are buying and if quality standards are to be capable of being monitored. The unique nature of community child health services, the range of purchasers (district health authority, FHSA, general practitioners, local authority), the range of providers, the interdisciplinary nature of the work and its locality base led to the conclusion that all purchasers should agree common service specifications supported by clinical policies. Competition was not seen as in the interests of children and their families, the purchasers, or the providers. Objectives are usually multiple and hence benefits may require a system of overwhelming dimensions to 'oversee' the whole system. There seemed to be a plea for common sense and stabilisation of the service after the changes in health, education, social services, and legislation. In contracting for long term health gain, the delegates accepted that factors outside the NHS were more important. Everyone, purchasers and providers, managers, and practitioners need to have a 'seamless mentality' coupled with a broad appreciation of the network as a whole. 'Child health' is a delicate ecosystem with balances between its different elements. It has served very well in the past; it may serve even better in the future provided that we appreciate its breadth and diversity.

We would like to thank the presenters for their contributions to the meeting: Mr M Ashman, Lincolnshire Social Services; Dr M 
Blair, Nottingham University; Mrs J Bracey, Nottingham Community Health NHS Trust; Dr S Coates, Sheffield Health Authority; Professor D Hull, Nottingham University, President, British Paediatric Association; Dr D Keen, Doncaster Health Authority; Mr C Moody, headteacher, Hardwick School; Mrs M Morgan, Nottingham Community Health NHS Trust; Dr J Moore, Leicestershire Health Authority; Mrs Z Plant, Nottingham Community Health NHS Trust; Ms S Stevens, Trent Health; Dr J Tresidder, South Derbyshire Health Authority. The following acted as facilitators for the afternoon workshops: Dr I Bowns, Barnsley Health Authority; Mr R Magowan, Trent Health; Dr P
Schatzberger, Trent Health; Ms S Stevens, Trent Health; Dr D Schatzberger, Trent Health; Ms S Stevens, Trent Health; Dr D
Spence, Trent Health. We are particularly grateful to Wendy Spence, Trent Health. We are particularly grateful to Wendy
Fauknall and Peter Conlan of Trent Health who provided invaluable organisational support.

1 British Paediatric Association. Community child health services an information base for purchasers. Working party report. Polnay L, chairman. London: BPA, 1992.

2 Court SDM, chairman. Report of the committee of enquiry on child health services. (Court report.) London: HMSO, 1976.

3 Trent Regional Health Authority. Report of the task group on the roles of FHSAs and community units. Alderslade $\mathrm{R}$, chairman. Sheffield: Trent Regional Health Authority, 1991.

4 Hall DMB, editor. Health for all children. Oxford: Oxford Medical Publications, 1991 .

5 Department of Health and Welsh Office. General practice in the National Health Service. A new contract. London: Department of Health and the Welsh Office, 1989.

6 Warnock M, chair. Report of the committee of enquiry into the education of handicapped children and young people. Special educational needs. London: HMSO, 1978.

7 Children Act. London: HMSO, 1989.

8 Polnay L. 'The community paediatric team - an approach to child health services in a deprived inner-city area.' In: Macfarlane A, ed. Progress in child health. Vol 1. Edinburgh: Churchill Livingstone, 1984.

9 The health of the nation. London: HMSO, 1992.

\section{Personal opinion}

Our paper points out the problems and complexities, outlines the main areas to be covered by the contracts, but gives no guidance on how to manage them. To the pessimist the area is a minefield; to the optimist armed with the right fertiliser, it is a garden waiting to flower. However, the difference between the optimist and the pessimist (as told to me by a Prague psychologist) is that the pessimist is better informed.

Child health services that are not part of an integrated service belong to community units or trusts. These organisations, like hospitals, are vast department stores. They have a wide range of goods and services that are diverse and specialist in nature. It follows that the purchasers and the providers should both possess a high level of specialist knowledge in the chosen area where they carry responsibility. This does not always seem to be the case and the NHS contracting process, resembles a theoretical scene in Harrods where the 'fruit and veg' man is left to decide the stock of Persian carpets. The clinical leaders and well informed purchasers should be those who negotiate the contract.

The department store model, with which we are struggling, is ridiculous and inappropriate for child health services. The community paediatric teams are much more like corner shops; they may be 'up market' in what they provide, but their services are closely linked to the locality and its population, about which they should have expert knowledge. Purchasing for a locality, talking directly to the shop manager, and allowing the shops to function as a franchise from the larger organisation would seem a good approach to take. If the locality has coterminosity with social service and education area offices, we will be in a position to negotiate a contract which is real currency for providing a package of services for children that is coordinated and really will meet their needs. The primary health care teams with practice areas in that locality can become a much more involved party in this local set of negotiations.

The model outlined above must have a public health strategy that is also able to recognise the health needs of pockets of population and the importance of meeting the needs of the education and social service departments (children in need). The relationship between the purchaser and provider is not simply a yearly event, but a year long event in which they both have oversight of the same population. Is that not what public health and community paediatrics are meant to be about? We would then have an informed discussion for the optimist and for the pessimist a lot of well designed plans that we cannot afford. I wonder who will turn out to be right? 